\title{
EXPLORING THE POSITIVE PSYCHOLOGY DOMAINS OF WELL-BEING ACTIVATED THROUGH CHARITY SPORT EVENT EXPERIENCES
}

\author{
KEVIN FILO AND ALEXANDRA COGHLAN \\ Department of Tourism, Sport and Hotel Management, Gold Coast Campus, \\ Griffith University, Queensland, Australia
}

\begin{abstract}
Charity sport events provide charities with an opportunity to promote the organization's mission, while providing participants with the opportunity to support the cause through participation. This research applies positive psychology to investigate well-being dimensions present in the event experience. Specifically, this study explores the five domains of well-being: positive emotions, engagement, relationships, meaning, and accomplishment (PERMA) among event participants. Five focus groups were conducted with participants from three different charity sport events. Directed content analysis results indicate that all five domains of PERMA emerged to varying degrees. The results provide implications for event managers to enhance the event experience, and bolster appeals for external funding, as well as a basis for further investigation of well-being and charity sport events in public health policies.
\end{abstract}

Key words: Positive psychology; Well-being; Charity sport events

Introduction

Large-scale sport events have become integral components of many regions' event portfolios. These events include marathons, walks, runs, and cycling rides. Beyond bolstering the image of a region, the events can promote active and healthy lifestyles within a community (Edwards \& Tsouros, 2008). The current research applies positive psychology to explore the domains of well-being within a specific category of large-scale participatory sport events: charity sport events.
Of the various types of charitable giving, Higgins and Lauzon (2003) argue that charity events are the most popular form of fundraising, perhaps as a result of their traditional market exchange characteristics. In particular, those events that offer hedonic value are the most likely to be supported (Peloza \& Hassay, 2007). There is a significant body of research indicating links between hedonistic experiences and aspects of well-being such as subjective well-being. Here we propose that within the context of charitable events, charity sport events may combine certain qualities of particular relevance to broader forms of

Address correspondence to Kevin Filo, Ph.D., Senior Lecturer, Department of Tourism, Sport and Hotel Management, Gold Coast Campus, Griffith University, QLD 4222, Australia. Tel: +61 (07) 555 28719; Fax: +61 (07) 555 28507; E-mail: k.filo@griffith.edu.au 
well-being. Specifically, these types of events offer opportunities to be physically active, support a worthy cause, achieve fundraising goals, and overcome physical challenges, while sharing experiences with other participants. The physical activity component of these events sets them apart from other charity events, such as the Leukemia Foundation's "World's Greatest Shave" or World Wildlife Fund's "Earth Hour." These events also support worthy causes, and may have excellent public awareness outcomes (Cheong \& Lee, 2010), but these initiatives are less likely to involve physically active challenges. This distinction is important as physical activity has a positive impact on well-being and health (Rasciute \& Downward, 2010). In addition, physical activity can induce positive moods, bolster self-esteem, and generate a sense of achievement (e.g., Biddle, Boutcher, \& Fox, 2000; Mutrie \& Faulkner, 2004), all of which are key components of well-being (Seligman, 2011).

Interestingly, of those events that do contain a physically active element, very little is known about the mental health and well-being outcomes of participation, while some evidence of physical health benefits has been revealed (Funk, Jordan, Ridinger, \& Kaplanidou, 2011; Maddock, 2006; Murphy \& Bauman, 2007). Studies in this context include the uncovering of motives driving charity event participation (Filo, Funk, \& O’Brien, 2008); an examination of the contribution of motives to meaning held for the event (Filo, Funk, \& O’Brien, 2011); and the investigation of the components of meaning derived from these events (Coghlan \& Filo, 2013; Filo, Funk, \& O’Brien, 2009). The current research extends existing knowledge through applying positive psychology to explore well-being outcomes of event participation among individual participants.

Positive psychology is the recent movement of psychology focused on optimizing the human living experience through the examination of outcomes such as: happiness, life satisfaction, and human flourishing (Seligman \& Csikszentmihalyi, 2000). Seligman (2011) has advanced five domains of well-being: positive emotion, engagement, relationships, meaning, and accomplishment (PERMA). This broader understanding of well-being encompassing both hedonic and eudemonic (i.e., flourishing) aspects has been supported by a number of researchers in this area (Gallagher, Lopez, \&
Preacher, 2009; Huppert \& So, 2013; Slade, 2010). As charity sport events include components such as fundraising for a cause (i.e., meaningful activities), teamwork (relationships), and physical challenge (engagement and accomplishment), PERMA can present a suitable framework to investigate these events and their impact on well-being. Accordingly, the current research applies PERMA to the event participant context. Specifically, the purpose of this research is to explore evidence for the expression of PERMA dimensions among participants' experiences within a charity sport event.

To address this purpose, qualitative data were collected via five focus groups with participants across three charity events each recruited through a convenience sampling frame. The three events from which participants were recruited include the Ballina to Byron Bay Charity Walk, the Cancer Council's Relay for Life, and the Multiple Sclerosis (MS) Swimathon. The manuscript encompasses the following sections; first, positive psychology is introduced as the framework for this research, including a review of PERMA. Next, the method for data collection is described, including details of the three events. From there, the results are detailed along with a discussion of findings, implications for managers, and directions for future research.

\section{Literature Review}

\section{Well-Being and Positive Psychology}

Well-being is strongly linked to health and happiness (World Health Organization [WHO], 2013); it is conceived as what is good for a person and how well that person's life is going for them. It is generally understood to be a subjective measure, unlike quality of life measures, which are often more objective (e.g., housing conditions, education, life expectancy) (Kahneman \& Krueger, 2006). Understanding of well-being dates back to the ancient Greeks, where Aristotle made the distinction between hedonic well-being or happiness and life satisfaction, and eudemonic well-being or a meaningful life. More recently, well-being scholars have added social well-being as a measure of social functioning, social support, and social contribution (Huppert \& So, 2013; Keyes, 1998). However, most researchers have focused on subjective 
well-being (SWB) as their measure of well-being, emphasizing the importance of high levels of positive emotions and moods, low levels of negative emotions and moods, as well as good evaluations of life satisfaction. This approach has been criticized by Huppert and So (2013), who argue that because these measures "arise from the perspective of pathology and tend to focus on functional limitations, they are limited value in describing positive aspects of functioning” (p. 838).

More recently, researchers have turned their attention to eudemonic well-being, particularly through the development of positive psychology and its contribution towards our understanding of human flourishing. Positive psychology reflects a movement within psychology extending beyond the traditional objectives of eliminating mental illness (Seligman, 2011). Specifically, positive psychology seeks relevance beyond individuals diagnosed with a mental illness to allow individuals to maximize well-being, maintain human flourishing, and live a good life (Seligman \& Csikszentmihalyi, 2000). In the evolution of positive psychology, the most recent trend has been towards an integrative well-being theory that encompasses the main findings across wellestablished constructs of happiness studies (Diener, 2000), flow and mindfulness (Csikzentmihaly, 1996), connectedness (Lee \& Robbins, 1998), meaning and purpose (Baumeister, 1992), and competence (R. M. Ryan \& Deci, 2000).

This integrative well-being theory proposed by Seligman and colleagues addressed concerns that prior studies of well-being placed too much emphasis on feeling good and cheerfulness, as for example in the established measures of subjective well-being and happiness. It also provided further recognition of the multifaceted nature of flourishing, as the highest expression of complete mental health and well-being (Keyes, 2002, 2007; Seligman, 2011). This wellbeing theory therefore suggests that integrated wellbeing linked to human flourishing and living a good life is comprised of five PERMA domains, namely positive emotions, engagement, relationships, meaning, and accomplishment. Within well-being theory, a single dimension does not define well-being, but each dimension does contribute to the construct overall (Seligman, 2011).

In outlining the five domains of well-being, researchers suggest that each dimension must have three properties. First, the dimension must contribute on its own to well-being. Second, each dimension must be pursued by an individual for its own sake, rather than pursued as a mechanism to obtain the other elements. Third, each dimension must be able to be measured independently of the other four dimensions (Seligman, 2011). Accordingly, well-being theory suggests that well-being is based upon cultivating one or more of the five domains of PERMA. The five domains of PERMA, and their relevance to charity sport events, are detailed next.

\section{Positive Emotion}

Positive emotions have been identified as a critical path to finding happiness (Seligman, Parks, \& Steen, 2004). The link between positive emotion and well-being was touched upon by Fredrickson's (1998) broaden-and-build theory of positive emotions. The theory states that positive emotions can work to broaden the way that an individual thinks and acts, while also building their physical, social, and psychological resources. The building of psychological resources includes resilience and coping, and Fredrickson (2001) suggests building this resource enhances an individual's well-being. Similarly, Tugade and Fredrickson (2004) revealed that positive emotions contribute to well-being.

Positive emotions include joy, interest, contentment, and love (Fredrickson, 2001). Exercise and physical activity have been found to positively influence mood (Fox, 1999), which can, in turn, lead to experiencing more positive emotions. The charity sport event experience provides a number of opportunities to experience positive emotions. For example, the physical activity inherent to an event, such as cycling $50 \mathrm{~km}$, may pique an individual participant's interest in that activity. Meanwhile, aspects such as fundraising or participating with friends and family can provide individual participants with joy. Qualitative data collected from event participants have included evidence indicating that positive emotions were present through event participation (e.g., Filo et al., 2008, 2009). These positive emotions were attributed to aspects of the event such as completion and supporting the designated charity, however, the specific positive emotions experienced were not explored. Theodorakis, Kaplanidou, and Karabaxogolou 
(2015) demonstrated that internal event factors such as personal performance and external factors such as event service delivery can lead to happiness experienced among participants. Accordingly, the current research further explores the engagement of positive emotions in the charity sport event context. Within the current study, positive emotion is conceptualized as affirming mental states experienced during charity sport event participation. The exploration of positive emotions in the charity sport event context leads to the first research question to be investigated:

Research Question 1: What evidence of positive emotion within the PERMA framework is revealed through charity sport event participation?

Despite the multitude of research on positive emotions and well-being, and the connection uncovered between the two, positive emotion cannot be used as a sole measurement of well-being. This is due, in part, to the fact that individuals do not experience positive emotions in the same manner (Hills \& Argyle, 2001), and positive emotions may be more salient in the "happy," hedonic sense of well-being, and contribute less to the "meaningful,” eudemonic sense of well-being (Forgeard, Jayawickreme, Kern, \& Seligman, 2011). This fact, along with the multidimensional nature of wellbeing, suggests other facets are important. Engagement is reviewed next.

\section{Engagement}

Engagement encompasses an individual being absorbed by an activity, while focused on what they are doing within that activity. Engagement in its ultimate state can be referred to as flow, and is characterized by: interest in the activity, a clear goal and a sense of control over the task at hand, a loss of sense of time, and complete concentration and immersion in the experience (Csikszentmihalyi, 1996). High levels of engagement have been linked to high levels of well-being (Kanste, 2011; Robertson \& Cooper, 2010). Low levels of engagement can facilitate a decrease in well-being (Frankl, 1966). Engagement has been uncovered and examined in both leisure (Duvall, 2011) and sport (Jackson \& Csikszentmihalyi, 1999).
Charity sport events would appear to be a context in which engagement takes place. The task orientation associated with preparing for and completing the event could foster flow. In addition, the goals connected to fundraising, completion, and timing may nurture engagement. From the tourism perspective, engagement and flow has been unearthed within activity and event contexts such as exploring cultural sites (Filep, 2014), white water rafting (C. Ryan, 1995), and scuba diving (Kler \& Tribe, 2012). Similarities between these activities and charity sport events (i.e., physical challenge, interacting with others, learning) suggest that engagement could be equally important to the charity sport event context. Meanwhile, evidence of flow has been uncovered in the sport event context (Marsh \& Jackson, 1999).

Although engagement has not been directly investigated in the charity sport event context, Coghlan and Filo (2013) did find that these events afforded an opportunity for participants to escape within the event through focusing on the task at hand. This initial evidence suggests engagement could be cultivated through these events. Forgeard et al. (2011) indicate that engagement "refers to a psychological state in which individuals report being absorbed by and focused on what they are doing” (p. 84). For the purposes of the current study, engagement is conceptualized as a state in which charity sport event participants find themselves absorbed in the event experience. Investigating engagement in the charity sport event context introduces the following research question:

Research Question 2: What evidence of engagement within the PERMA framework is revealed through charity sport event participation?

Beyond the individual focus within engagement, interactions with others may contribute to wellbeing. Relationships reflect the importance of others in well-being.

\section{Relationships}

The emphasis placed on relationships is evident in the evolutionary importance of recognition and interaction with others (Frankl, 1996). In addition, some of the crucial human needs advanced 
by Maslow's (1968) hierarchy of needs, including safety, belonging, love, and esteem, are based upon developing relationships with others. Strong relationships with others are central to well-being (Diener \& Seligman, 2002). Meanwhile, the importance of relationships is highlighted across an array of positive psychology and well-being research (Peterson, 2006; Peterson, Park, \& Sweeney, 2008; Reis, Sheldon, Gable, Roscoe, \& Ryan, 2000).

A great deal of evidence suggests that relationships are an important component of an event experience. Brajša-Žganec, Merkaš, and Šverko (2011) revealed that participating in cultural events (i.e., concerts, sport events, exhibits, and theater) helps to build social relationships, which in turn positively influences subjective well-being. The social motive has been highlighted as a factor that drives charity event participation, and also takes on greater meaning during the event (Filo et al., 2008). In addition, camaraderie has been identified as a factor contributing to the meaning derived from the event (Filo et al., 2009). The current research extends these findings through an investigation of relationships among charity sport event participants. Forgeard et al. (2011) align relationships with social support and advance these constructs as "the belief that one is cared for, loved, esteemed, and valued” (p. 86). The current study conceptualizes relationships as experiencing togetherness and belonging during the charity sport event experience. This introduces the third research question posed within the current study:

Research Question 3: What evidence of relationships within the PERMA framework is revealed through charity sport event participation?

Meaning reflects an additional dimension of well-being that has been previously discussed in the charity sport event context.

\section{Meaning}

Meaning embodies an individual deriving purpose from life (Forgeard et al., 2011). Having meaning in one's life has been found to contribute to well-being (Scannell, Allen, \& Burton, 2002). An important component of meaning is a broader, more selfless purpose inherent to a meaningful life. For instance, having children contributes to the meaning derived from life among parents (Baumeister, 1992). In addition, civic activities and church groups have been identified as entities that provide a life with purpose, and in turn, meaning (Seligman, 2004). The current research builds upon this notion through examining meaning from the perspective of event participation, as well as stemming from the charitable component of the event. Each of these event components can provide meaning to participants.

Meaning has been revealed as a central aspect to the charity sport event experience, with a variety of factors contributing to the meaning derived (Coghlan \& Filo, 2013). In addition, the emotional, symbolic, and functional meaning drawn from an event has been the focus of select research (e.g., Filo et al., 2008, 2009, 2011). The current study distinguishes from this research in that rather than focus on the event as a meaningful experience, the event is instead portrayed as an opportunity for participants to gain a sense of purpose and meaning. In this way, the current research represents a direct response to calls for qualitative investigation of meaning through allowing individuals to reflect upon experiences (e.g., Filep, 2014). As noted above, the social component and the charitable aspect of the event reflect aspects of the event from which this meaning can be gained. Meaning has been defined as the feeling of belonging to something larger than oneself (Seligman, 2011). For the current research, meaning is conceptualized as the sense of purpose individuals derive from feeling a part of something larger than themselves through charity sport event participation. Meaning advances the fourth research question:

Research Question 4: What evidence of meaning within the PERMA framework is revealed through charity sport event participation?

The final dimension of well-being is accomplishment.

\section{Accomplishment}

Accomplishment is conceptually close to achievement and autonomy (Forgeard et al., 2011). Deci and Ryan (2000) indicate that competence and sense of achievement allow an individual to satisfy needs and enhance well-being. Seligman (2011) advanced 
accomplishment as critical for well-being because recognition of the construct is an important human need. Given the goals and standards inherent to physical activity (e.g., timing races, improved fitness), accomplishment is central to activities such as events. To illustrate, Stevinson and Hickson (2013) found that factors such as improved physical fitness and health benefits were critical factors for participation in a community sport event. Furthermore, it was revealed that the achievement of these objectives translated to reporting improved confidence and mental well-being.

Existing research in the charity sport event context suggests that accomplishment is important. The physical motive has been identified as a driver of event participation (Filo et al., 2008). In addition, competency is a factor that underlies attachment to charity sport events (Filo et al., 2009). Accordingly, accomplishment is investigated in the current research as the fifth and final component of wellbeing. Accomplishment is revealed through achieving a goal within a specific context (Forgeard et al., 2011). The current research conceptualizes accomplishment as the sense of achievement derived from obtaining goals and pushing personal boundaries through charity sport event participation. Examining this sense of achievement leads to the final research question addressed within the current study:

Research Question 5: What evidence of accomplishment within the PERMA framework is revealed through charity sport event participation?

In summary, well-being theory posits that wellbeing is multidimensional and comprised of five domains: PERMA. Well-being can be examined globally or contextually, and coming to an understanding of contextual well-being can provide insights into optimizing well-being overall (Diener, Suh, Lucas, \& Smith, 1999). The current research explores well-being in the context of charity sport events. The method employed to address the five research questions is outlined next.

\section{Method}

To address the five research questions advanced, qualitative data were collected via five focus groups with event participants in the months following three different events. An overview of the different event contexts is provided below. From there, the participants, materials, and procedures employed within the focus group are detailed.

\section{Event Context}

The first event was the inaugural Ballina to Byron Bay Charity Walk to raise funds for the Westpac Life Saver Rescue Helicopter in northern New South Wales, Australia. The event is organized by the staff and volunteers of the service to celebrate the helicopter's free community service delivering aeromedical service to the community free of charge for over 30 years. The service has saved over 6,500 lives within the community. The Ballina to Byron Bay Charity Walk attracted over 540 participants, who collectively raised over $\$ 40,000$ for the Westpac Life Saver Rescue Helicopter in 2012. The event encompasses a 37-km walk beginning at 6:00 am on a Sunday. Participants are required to organize a team of individuals to complete the walk. At the conclusion of the walk, a postevent gathering is held consisting of a BBQ for participants, friends, and families along with an awards presentation. One focus group was conducted with participants in this event.

The second event was the Cancer Council's Relay for Life taking place in southeast Queensland, Australia. The event is designed to celebrate cancer survivors, remember loved ones lost, and fight back against cancer through funds raised for research and treatment. The event goes back to 1985 when Dr. Gordy Klatt ran and walked around an oval for $24 \mathrm{hr}$ to raise awareness of cancer and funds for cancer treatment. The Australian events are held in many places across the country and collectively raise over \$14 million each year. Teams of walkers relay through the night to keep a baton moving around a designated track (usually an oval). Teams are encouraged to develop a team theme, dress up, and make the relay fun, while the event includes a Survivors Walk and Candlelight Ceremony as highlights of the experience. The second, third, and fourth focus groups for the current research were conducted with participants in the 2013 Relay for Life on the Gold Coast, Australia.

The third and final event was the 2014 MS Swimathon in Gold Coast, Australia. This event is 
a Queensland-based fundraising initiative for MS Queensland to support Queenslanders living with multiple sclerosis. Events are held in seven locations across Queensland, and raised over $\$ 170,000$ in 2014. Teams of up to 12 people swim in a 12-hr relay. Similar to the Relay for Life, participants are encouraged to participate in novel ways through team dress and support of other teams. The event includes multiple "Hours of Power" wherein participants are encouraged to swim as many laps as possible in $60 \mathrm{~min}$. Prizes are given to participants and spectators at the conclusion of the event. The fifth and final focus group conducted for the current research comprised of participants in the MS Swimathon.

\section{Participants}

The focus groups consisted of 2-5 participants, representing a total of 19 respondents $(n=4, n=4$, $n=4, n=5, n=2$ ). Although these participant numbers are lower than the suggested range of 6-8 individuals per focus group, this method was still employed as the research team was exploring how individuals think and feel about a product (i.e., charity sport events) (Krueger \& Casey, 2002). In addition, the group dynamics inherent in focus groups aligned with the notion that each event was completed as a group (i.e., as a team; as a community). Their ages ranged from early twenties to late fifties. Thirteen participants were female. For the Ballina to Byron Bay Charity Walk, the demographic breakdown of event participants overall aligned with the demographics of the first focus group, as the participant base was $80 \%$ female and between the ages of 20 and 50 . The demographics of Relay for Life participants within focus groups two, three, and four (individuals were predominantly in their early twenties, and 60\% were female) align with the demographic breakdown of event participants overall. The MS Swimathon reflected broad demographic distribution including a high percentage of young adults as well as families. The two participants in the fifth and final focus group were two females younger than age 25 .

\section{Materials}

The researchers developed a list of possible questions for the focus groups. The questions were created with the objective of allowing each focus group participant to illuminate examples of the domains of well-being experienced through the event. The list of questions was used within each focus group, but questions were asked in such a way as to follow from the responses provided by the focus group participants (Seidman, 1998). The complete list of questions employed within the focus groups is included in the Appendix.

Prior to commencing the focus groups, the researchers allocated time to allow participants to get comfortable in the room. This included the provision of refreshments. From there, the researchers introduced themselves to each participant, while supplying background on the research project. Allocating this time for introductions, background, and comfort was used to establish rapport among the group (Fontana \& Frey, 1994), as well as to let the event participants reconnect and reminisce about the event.

\section{Procedures}

The focus groups were conducted after ethical clearance had been obtained from the researchers' institution. Participants in the first focus group were recruited via e-mail invitation to an individual who had organized a team for the event. This individual then recruited the additional members of the team, and the researchers worked with all four participants to coordinate a date and time for the focus group. This recruitment and coordination took place 3 weeks after the event had been completed.

Meanwhile, participants in focus group two, three, and four were recruited via an e-mail from the event organizer to the database of 250 individuals 4 months after the event. Relay for Life participants were asked to contact the lead researcher to schedule the focus groups. Twelve participants initially contacted the researchers, while an additional participant contacted the lead researcher on behalf of a team of five participants interested in taking part in a focus group. Consequently, 17 individuals were scheduled for three focus groups; however, there was withdrawal across each session as individual participants did not attend as scheduled. Specifically, one individual was unable to attend the second focus group, one participant did not show up for the third focus group, and one participant did not attend the fourth focus group as originally 
confirmed. In addition, two individuals did not follow up with the researchers after responding to the initial invitation e-mail.

Participants in focus group five were recruited at the event. The lead researcher attended the MS Swimathon to introduce the research project and invite participants to get involved through requesting their e-mail address. Approximately 130 individuals participated in the event. Three individuals expressed interest and provided their e-mail address to schedule the focus group. Once again, there was attrition, as one individual did not attend as had been indicated. Focus group participants were provided with the aforementioned refreshments and gift vouchers as incentives for taking part in the research.

The focus groups were conducted by two researchers, each of whom was trained through having conducted multiple focus groups across their respective careers. With each participant's permission, the focus group was audio recorded by the researchers. The focus groups lasted between $40 \mathrm{~min}$ (for the smallest group) and $90 \mathrm{~min}$. After completion of each focus group, the recordings were submitted to a third-party transcription service to prepare for analysis.

\section{Limitations}

Limitations of the current research should be acknowledged given the exploratory nature of the research design. First, the sampling frame for this research reflects a limitation. A convenience sample of four individuals was employed for the first focus group. From there, convenience samples were again utilized for the remaining four focus groups based upon individuals who were willing and able to meet on the designated dates and times presented as options. This poses questions regarding the rigor behind the data collected. However, the sampling frame used allowed the researchers access to initially explore the ideas presented in this project. Furthermore, convenience sampling can be used for practical purposes in academic research (Corbin \& Strauss, 2008). In this instance, the date, time, and location presented logistics around which the researchers had to work via convenience sampling.

Beyond the convenience sampling approach utilized, the use of multiple recruitment strategies reflects a limitation of the current research. The first focus group was organized via direct contact with a team member (and team organizer). The second, third, and fourth focus groups were recruited through an e-mail sent from the event organizer, and this took place a number of months after the event. Participants in the fifth and final focus group were recruited at the actual event. These different strategies reflect the challenges experienced by the researchers in recruiting participants. Consequently, the researchers determined that attending the event could stimulate increased interest, whereas recruitment via an e-mail from the event organizers received a limited response. This turned out to not be the case, and the different mechanisms used to recruit participants could have influenced our findings in that there may have been increased rapport with participants in the first and fifth focus groups due to the more direct approach taken by the research team.

Second, the amount of time between the actual event and conducting each focus group could have impacted the data. Allotting a number of weeks between the event and data collection was done for pragmatic and theoretical reasons. From a practical perspective, the later date suited the researchers, available participants, and additional stakeholders such as event organizers in the case of the Relay for Life. From a theoretical perspective, the researchers felt that allowing for additional time from the event to pass would facilitate participant reflection upon the event. Allowing for several weeks to pass between the conclusion of the event and data collection has been previously used in qualitative investigations in which participants reflected on a sport experience (Sherry, 2010). However, the lapse in time, particularly with the Relay for Life focus groups, could have impacted participant recollection. In addition, the qualitative data collected reflects subjective assessment of PERMA exclusively. Although select domains of PERMA can only be examined from the subjective point of view, support exists for a mix of both subjective and objective evaluation of wellbeing in general (Forgeard et al., 2011). Again, given the exploratory research design, the qualitative data collected is positioned as a starting point.

\section{Data Analysis}

Each focus group was audio recorded and transcribed verbatim at a later time. The data generated 
from the transcriptions were then analyzed using a directed content analysis approach (Elo \& Kyngas, 2008). Unlike an inductive content analysis, where codes are generated in a bottom-up approach from the data themselves, directed content analysis uses a deductive approach, using existing theory to create prior formulated, theoretically derived codes and determining how and when these apply to the text (see Mayring, 2000, for steps in the deductive or directed content analysis approach). Directed content analysis can be used to extend a preexisting theoretical framework, and the findings from this approach offer supporting and nonsupporting evidence for a theory within a specified research context, thereby focusing or refocusing the original research question (Hsieh \& Shannon, 2005). Findings are most commonly presented using exemplars and by offering descriptive evidence of codes that are predetermined by the theory, often combined with a quantitative step such as a frequency count during the interpretation of the results (Mayring, 2000). In the case of the current research, the PERMA themes and corresponding well-being domains derived from well-being theory represented the preexisting framework guiding the data analysis approach.

The strength of directed content analysis is that the approach can support or refute existing theory in a given research context (Elo \& Kyngas, 2008; Hsieh \& Shannon, 2005; Mayring, 2000). Inherent to this approach, however, is the limitation that researchers approach the data analysis with an "informed, but, nonetheless, strong bias" (Hsieh \& Shannon, 2005, p. 1283), which is more likely to lead to evidence that is supportive rather than nonsupportive of a theory. On the other hand, it makes explicit that researchers are unlikely to be working from a naïve perspective used in other types of qualitative data analysis.

After these predetermined codes were applied and counted, each was sorted with specific data extracts (i.e., direct quotations from focus group participants). These themes and data extracts were then reviewed for overlap and homogeneity. Within this review process, the first and second author met to review the data extracts and frequency counts for each theme. The coauthors were in agreement regarding the frequency of themes and the corresponding data extracts. Finally, the remaining data were coded for additional themes not related to PERMA, again following the procedures set out by directed content analysis. The results from these analysis efforts follow and are described narratively below with sample quotes to reflect participant attitudes and feelings.

\section{Findings}

The results are presented below using direct quotes from the focus group members. The evidence supporting each domain of well-being is presented. In accordance with directed content analysis, frequency counts for each theme were tabulated (Mayring, 2000). All five of the PERMA dimensions were present, albeit to varying degrees. In addition, some overlap among themes was noted and this is reported in a separate subsection. Finally, five themes not related to PERMA are also acknowledged. Participant pseudonyms are used to introduce each quote provided below, along with the respective focus group number (e.g., FG1-5) in which each individual was involved.

\section{Positive Emotion}

All focus group participants agreed that positive emotion was experienced throughout the event. This was revealed through all participants indicating that they had experienced positive emotions when the second series of questions within the interview guide was asked: What was the most enduring positive emotion that you experienced during the event? After the event? Can you recall any less positive emotions? Specifically, in response to the third question in the series, all focus group participants shared that the event had elicited positive emotions. Overall, 78 instances of supporting evidence (i.e., direct quotes from focus group participants) were found for positive emotion. Notably, however, respondents often struggled to articulate the specific emotions elicited when prompted. Kendra (FG1) attempted to detail positive emotions experienced by expressing the following: "I think it was the scenery. . . . It was such a beautiful day. Being able to walk along all of those beaches." From there, Melissa (FG1) concurred: "I think it's just appreciating beauty and excellence." Further questioning by the researchers in each of the focus groups elicited the following emotions: 
gratitude and appreciativeness, hope and inspiration, pride (and relief), and finally, happiness. Gratitude emerged as a positive emotion experienced as individuals described their appreciation of the experience afforded by the event. Belinda (FG1) stated, "I was just endlessly grateful of where we live and that we are healthy enough to do it.” Libby (FG3) alluded to gratitude as well in saying that she was "thankful for everyone being in that moment." Christopher (FG3) touched upon his gratitude and appreciation for the event experience: "I just thought to myself how lucky we are to live in a country where we can have this sense of community."

Feeling hopeful and inspired were captured by statements such as "I was very hopeful at this event because it was for such a great cause so everything that happened was so positive . . . so it just gave you that sense of hope" (Kimberly, FG2) and "the whole thing was incredibly uplifting” (Sally, FG4). Other respondents identified feeling relief and pride at finishing the walk. Further analysis of the transcripts revealed a number of other emotions: kindness and generosity through giving to the charity, feeling loved by other participants, increased self-confidence and euphoria upon completing the training and the event, encouragement towards and from teammates, and finally, fondness among participants. The emotion "happiness" was mentioned 17 times in the five focus groups, with Mindy (FG5) simply stating “I felt happy, yes” when describing how participating in the event made her feel.

Melissa (FG1) provided evidence of the emotions inherent to the event experience. She simply stated: "I think I burst into tears, because we did it." The focus group participants unanimously agreed that the event evoked positive emotions. However, questions attempting to probe specific positive emotions, along with examples illustrating these emotions, were sometimes unsuccessful and the range of emotions identified in this way was limited. Difficulty in articulating particular emotions is evident in the following description from Sally (FG4): "I felt really privileged to be there. I don't know, it just made me feel so proud ... I felt really good.” These results perhaps reflect Seligman's (2004) distinction between experiencing pleasure (i.e., a hedonistic experience), where respondents are usually able to describe a conscious and felt positive feeling, and experiencing gratification (an experience of flourishing), which is associated with elusive feelings, which can only be accessed with difficulty.

\section{Engagement}

Engagement was the least frequently encountered theme among the five PERMA dimensions, with only 18 occurrences across the five focus groups. The first focus group interpreted engagement as the absence of talking during the walk. For instance, Constance (FG1) said "I think we had a moment, Kendra and I. I think at one stage we were just talking and the next minute we weren't.” From there, Constance affirmed her position, and further illustrated the moment: "I think we kind of both realized at the same time, 'Wow, we just didn't say anything there.' We were really focusing on the walk." The notion of focusing on the activity alongside another participant leading to engagement was also described by Adrian (FG3):

I spent a fair bit of time walking with a good friend of mine in the student mixed team and while I was walking with her, I didn't really focus on how many laps we'd done or the time that had passed, we just kept walking and it was incredible I think the number of laps we would have got done in that time that we were walking. We started pretty much at the start of the event and it was dark by the time we had a bit of a break so that was probably the biggest moment when I got lost in the moment.

Instances of engagement did appear within the other focus groups, particularly during moments of the event designed to create a space for personal reflection. In the Relay for Life event, participants walked with lit candles to honor those affected by cancer, and later released balloons carrying messages of hope for cancer survivors. Respondents recalled these moments as fostering a sense of engagement. For example, Katherine (FG2) offered:

I think when you had it [the balloon] and you were letting it go, you were thinking about yourself and your own journey and the fact that you'd done it. And then as soon as you let it go and you look up and you see there was hundreds in the sky. It was pretty special.

In addition, respondents reported quiet moments of reflection underscoring engagement. Libby (FG3) 
indicated, "It was a reflective time where we all ... we were still chatting but we were all very reserved and aware of where we were and what we were doing." Libby (FG3) later elaborated further on concentration throughout the event allowing for engagement:

I suppose whenever I was doing something whether it was on the track or an activity or listening to the band, I wasn't really thinking about anything else. I suppose I was always just doing what we were there to do.

Francis (FG5) detailed heightened sensory engagement as well:

I was surprised that I was lost [in the moment] when I was swimming because it used to be always such a struggle for every breath and every stroke but, yes, I felt like it was just feeling the water flowing through fingertips.

\section{Relationships}

Throughout the focus groups, participants provided over 88 examples of the relationships experienced and engaged during the event. These examples included togetherness felt during the event, the strengthening of existing relationships among participants with their friends, and initiating relationships with other participants. In describing the relationships that emerged, participants detailed the connection shared with others. Participants crossing the finish line arm in arm illustrated this connection. Melissa (FG1) stated: "Together. We did it together, arm in arm.” A sense of togetherness was also referenced by Sally (FG4): "So many people were banding together to try and fight it [cancer]."

The relationships experienced by participants were also illuminated amid discussion of an individual who experienced an injury during the course of the Ballina to Byron Bay Charity Walk. Melissa (FG1) introduced this incident and relayed it in terms of strengthening relationships within her team:

I very much felt part of a group. . . . An example I could give is when [the injured teammate], her leg started to go, and she could no longer walk quickly. She was in pain. I walked very close with her. We told each other jokes and sang songs to help her through the pain.
Individuals described relationships with other participants via support and encouragement expressed throughout the walk. Belinda (FG1) highlighted interactions with other participants and provided an example of this mutual support:

The other thing that happened at the very last bit was as we were going up the lighthouse there was a woman who was in really bad straights. She was all by herself. She was sitting down. She looked really unwell. There was nobody else around. You know, we all stopped. We were not quite together. A couple of you guys were ahead or something. We stopped and we stayed with her until somebody came to look after her because there were first aid people around. I thought that was really impressive too. It was not like, "Oh, bad luck, she's not on our team." It was like, "Of course you're going to help this person. She doesn't look well."

Francis (FG5) suggested that existing friendships with fellow participants were strengthened as a result of experiencing the event together: "We've been friends for a long time but then supporting them in something like that makes you more likely to call them up for a movie or to the house.” This connection to other event participants was noted by a number of respondents in statements such as this from Naomi (FG2): "We heard a lot of different people's stories and it was a sort of thing when we were at the event you're making friends with everyone and people going around giving free hugs and the camaraderie between everyone.” Libby (FG3) shared a similar sentiment:

I felt there was a lot of bonding between other teams and making sure everyone had a good night and then with the competitions they were doing there was one team who was 50 cents a hug so you get to know people and built the relationships through that through the night and we were all there for the same reason so everyone cheered people on.

The relationship domain was particularly poignant when respondents referred to a connection shared with participants who had personal experience with the cause that the event was targeting. Sara (FG4) described the following scene:

When we went to do that honor lap and some of the people were getting up on stage and they were actually telling their story like how they were even 
in remission. There were some elderly people there they were struggling on that walk but they just looked so happy to be there, to be amongst everybody, that's the feeling I got even though they'd gone through a terrible journey themselves, that honor lap and people talking about it I think did actually link those people.

The togetherness and belonging referenced as participants expressed relationships reflects the influence of others. Meaning represents an additional domain that goes beyond the individual.

\section{Meaning}

Participants derived a great deal of meaning from the event experience, and provided 43 instances of meaning related to the event experience. The sense of feeling a part of something larger is embodied in the following quote from Carl (FG4): "Playing our bit in the wider bit to have that sense of purpose and then the faith that it's going to go somewhere.” Melissa (FG1) expressed meaning drawn not only from the completion of the event, but also in terms of the training required: "I loved the training. I loved the training for it. It gives you purpose." Participants also described meaning in terms of the sense of purpose obtained from supporting the charity. Kendra (FG1) expressed the meaning associated with supporting a charity in need:

I guess it comes back to what she was saying in terms of, I like the fact that this was also a charity event. We were able to raise money not for a really massive charity that tends. . . . All charities obviously are important, but not something that gets a lot of money all the time. It's a small charity. It's for the local area.

The charity, and the broader cause linked with this charity, was a source of meaning for Relay for Life participants. Libby (FG3) described her internal monologue throughout the event: "I kept reminding myself that we're here for that reason, to help find a cure and that kind of got me through the night, thinking it was a big goal at the end of it."

Melissa (FG1) suggested that participants experienced being a part of something larger than the individual through "a great sense of team spirit." Belinda (FG1) explicitly detailed how the event allowed her to feel a part of something larger than the individual, and even the team: "but that struck me too, that whole sort of 'this isn't about us as a team winning. It's about an event and collegiality and wanting everyone to finish.' ",

Meaning was further underscored by the perspective on life provided through the event experience. Mindy (FG5) indicated that the event represented: "Something good in the world. For me it was being positive and seeing the good side of things, it's not so horrible." Similarly, Jackson said (FG4): "I think it gave me a real perspective like in terms of exposure to people who've beaten cancer.” Meanwhile, Amanda (FG2) detailed realizations that occurred during the event:

Everything that happened in the event it made me realize how important life is and how it influences everyone else's around you and you don't take anything for granted. Hearing the speeches of the cancer survivors makes you realize how beautiful life is and that you should take every moment as it comes.

\section{Accomplishment}

Accomplishment emerged throughout the focus groups, and 49 separate instances relating to accomplishment were identified in the transcripts. Kendra (FG1) described her feelings upon completion as a "Sense of achievement, not only for yourself, but for the charity." A sense of achievement was frequently described in terms of the physical aspect of the event, specifically the event as a means to push physical limits. For instance, Mindy (FG5) stated:

I liked the challenge as well. I hadn't been in the pool to swim for that long in a long time, probably years, so I was really interested in knowing whether I could do it and looking for that opportunity where I could swim as many laps as I possibly could. That was a very cool thing.

Accomplishment was further described in terms of the confidence gained from pushing personal boundaries through training and completing the event. Melissa (FG1) indicated that the event was good for "my self-esteem, which increased tremendously." She followed this by saying that "I sort of rediscovered physical confidence in myself that had slipped to a certain extent, and I'm continuing that.” Accomplishment was further alluded to 
in terms of the fundraising aspect of the event. For example, Libby (FG3) stated:

I think it was really huge and the fact that we raised over $\$ 40,000$, that's just phenomenal . . . so I think there was a massive sense of achievement from everybody from those who competed for 5 minutes to those who competed for the whole 18 hours.

The broader mission of the event was positioned as a point of accomplishment by Kimberly (FG2): "Working to achieve a better future that was kind of the whole point of the event" as well as Adrian (FG3) who summarized completion of the event as: "actually trying to make small little steps towards achieving things through cancer research." Collectively, the results indicate that focus group respondents experienced accomplishment through the event.

\section{Overlapping Themes}

In many instances, two or more dimensions of PERMA appeared together in the participants' responses to the focus group questions. This was particularly true of positive emotions and relationships (appearing together in 14 counts), meaning and relationships (8 counts), and positive emotions and meaning (7 counts). An example of emotions and relationships overlapping was provided by Naomi (FG2): "I think we just felt really proud too together as a team, the fact that we were there and that we'd done it and that we were participating. Proud of ourselves, proud of each other and, yes, it was just really nice.”

An example of meaning and relationship was provided by Libby (FG3):

I just felt a great sense of closure for the event like we'd completed this and yet we're still sending out these messages of hope and love and positivity and prayers for the future and watching those balloons float away. It really highlighted what we'd just done and dreamed about for the future. I really felt it was a great way to end it because it was so beautiful and a nice thought that all our positivity was being released and seeing that was quite nice.

The combination of positive emotion and meaning was captured by Carl (FG4):
The honor lap, when we got to see that it was pretty moving I guess and you can see this is what we're donating to, this is why we're doing this and so I guess you feel good inside yourself that you've done something even though it's a minimal contribution but it's better than nothing.

Finally, in four instances, respondents described a complex blend of meaning, relationships, engagement, and accomplishment. For example, Kendra (FG1) stated:

I still come back to the people, the community spirit of doing that walk. Everyone there was for that one purpose, to raise funds, and also to probably challenge themselves, prove to themselves they could do the walk. I just couldn't get the smile off my face. Everyone there is just for the same. ... It just felt nice and normal. It was good. That's what I liked about it.

\section{Nonsupporting Themes}

Consistent with the protocol for directed content analysis, the authors also analyzed the data to identify themes outside of PERMA (Hsieh \& Shannon, 2005; Mayring, 2000). Within this identification of themes that did not support the PERMA framework, the authors once again totaled the frequency for each theme. Overall, five themes were identified: challenge, intention to participate again, novelty/play, learning/homage, lack of solidarity. These are presented in Table 1, along with their frequency and example quotations for each nonsupporting theme. In accordance with directed content analysis, it is important to identify and highlight these nonsupporting themes, however no further analysis is provided as these are not the core focus of our article.

\section{Discussion}

The results presented in this study indicate support for the presence of the PERMA domains of well-being within charity sport events, albeit to varying degrees. Collectively, this support addresses each of the five research questions, indicating that evidence of the five domains of the PERMA framework are revealed through charity sport event participation. Understanding how PERMA might be expressed through such 
events has important managerial implications, as well as broader public health considerations, and finally, this can extend our conceptualization of how PERMA may be operationalized, and of wellbeing domains more broadly. These are discussed in turn below.

\section{PERMA Domains in Charity Sport Events}

The contribution of PERMA domains to wellbeing, as a result of participating in charity sport events, is neatly captured in the following quote by Melissa (FG1):

I really was very down last year. This is part of me realizing and knowing, also from the positive psychology side of things, knowing that happiness isn't something that just comes to you. You have to actually take steps to improve your own emotional well-being and sense of social well-being and physical well-being. Yeah, it takes effort, but it's so rewarding.
The domains of positive emotion, relationships, meaning, and accomplishment were the most clearly articulated, perhaps being most closely linked to the social, physical activity-based, and charitable nature of such events. In particular, the central role of relationships was highlighted during much of the focus groups and may reflect the sense of connection that is fostered through these events (Coghlan \& Filo, 2013), and more broadly, the camaraderie inherent to charity sport events (e.g., Filo et al., 2009).

Positive emotion was the second most evident PERMA domain across the five focus groups, yet a number of individuals struggled to state which positive emotions were felt. Positive emotions are generally challenging to evoke qualitatively, as they are more diffuse and less urgent than negative emotions, which tend to provoke a stronger response (Fredrickson \& Cohn, 2008). Furthermore, based on Seligman's (2004) distinction between pleasure (associated with conscious positive emotions) and gratification (associated with elusive feelings),

Table 1

Additional Themes Identified Through the Directed Content Analysis

\begin{tabular}{|c|c|c|}
\hline Theme & Frequency & Example \\
\hline Challenge & 15 & $\begin{array}{l}\text { "I think I was just really amazed by my friend John who was competing } \\
\text { with his mate Daniel from the business school. They were trying to do } \\
\text { the most laps and I just gained a lot of respect for him because I was like } \\
\text { wow, it's amazing how he kept doing it the whole night. I've forgotten } \\
\text { how many Ks he did but it was insane and I was amazed that some of } \\
\text { the students have such strong perseverance." (Christopher, FG3) }\end{array}$ \\
\hline Intention to participate again & 5 & "Yeah. I'm going to do it again next year.” (Belinda, FG1) \\
\hline Novelty/play & 18 & $\begin{array}{l}\text { "These guys had a ball so my goal was to just keep stealing the ball and } \\
\text { other people had skateboards and stuff like that, I was trying to chase } \\
\text { them and make them do more laps and stuff like that. So I basically } \\
\text { played for the whole } 18 \text { hours and tried to do pranks on people and stuff } \\
\text { like that." (Sara, FG4) }\end{array}$ \\
\hline Learning/homage & 26 & $\begin{array}{l}\text { "I did learn about MS a little bit more in detail and the one thing that } \\
\text { actually surprised me about it was that it is most common in women } \\
\text { between } 20 \text { and } 30 \text { and that was a bit more of an interesting statistic } \\
\text { around that. I didn’t know it was a young person's ... that young people } \\
\text { are able to get the disease as well, that there were plenty of younger } \\
\text { victims or patients." (Mindy, FG5) }\end{array}$ \\
\hline Lack of solidarity & 8 & $\begin{array}{l}\text { "Some members of the team, spending the } 24 \text { hours with them, showed } \\
\text { you how disinterested they may have been in the event itself. One mem- } \\
\text { ber of the team I think was there for an hour and didn't see him again } \\
\text { after that. The other guy stayed for a couple of hours but then went into } \\
\text { one of the other buildings and didn't see him again after that. So I may } \\
\text { have expected that if people were going to participate in this charity } \\
\text { event and being such a major charity event at the university then they } \\
\text { might have put in a little bit more effort than that." (Adrian, FG2) }\end{array}$ \\
\hline
\end{tabular}


it is likely that charity sport events elicit a greater sense of gratification than pleasure. A number of references to gratification were made throughout the focus groups. Additional investigation of the positive emotion domain in the charity sport event context is therefore warranted, with particular reference to the distinction between pleasure and gratification.

The domain of accomplishment was evident both through the achievement of goals in training and the completion of the event, as well as personal boundaries pushed within participation. These components relate closely to the sense of competency offered through these events (Filo et al., 2009). The focus group results provide further support for the relationship between physical activity and well-being (Biddle et al., 2000; Mutrie \& Faulkner, 2004; Rasciute \& Downward, 2010). The fourth PERMA domain that emerged particularly strongly from the results was a sense of meaning; the training required for the event, along with supporting a charity and feeling a part of the team and/or community of participants provided purpose.

Evidence of engagement was less obvious in the results. Participants were unable to fully describe engagement within the event experience. Despite the many event factors and design characteristics central to experiencing engagement, this domain was the least frequently counted across the five focus groups. In some instances, focus group participants were openly debating whether engagement took place during the event experience, while other individuals were able to share illustrative examples of total absorption in the event, or particular moments within the experience. This could be attributable to challenges that exist in describing and measuring engagement (Forgeard et al., 2011).

\section{Managerial Implications}

The findings from this study suggest that event managers could capitalize on the well-being domains of the event. First, by being aware of the PERMA domains present in charity sport events, event managers can design their events to maximize opportunities to develop and strengthen relationships, foster a sense of meaning, as well as experience positive emotions and accomplishment. There has been increased emphasis on using design to facilitate social interaction at events to allow for socialization with friends and family as well as to meet new people (e.g., Nordvall, Pettersson, Svennson, \& Brown, 2014). This aligns with focus group participants indicating that the event experience allowed them to strengthen existing relationships with other participants along with initiating new relationships. Fostering socialization through event design could also contribute to meaning via social cohesion, allowing individuals to feel a part of something larger than the individual (Schulenkorf, Thompson, \& Schlenker, 2011), and accomplishment via feeling achievement in meeting people and/or bolstering existing friendships.

An example of a charity sport event that has succeeded in this regard is the LIVESTRONG Challenge. The event includes components such as a fundraising appreciation dinner the night before the event, the LIVESTRONG Challenge Village featuring vendors, food stalls, and a kids' zone, as well as a beer tent. Both the LIVESTRONG Challenge Village and beer tent are open to participants and spectators, and the grounds are designed to facilitate socializing and sharing the event experience.

Second, event managers can create avenues to allow participants to describe their experience and the impact the event has had on their well-being. Storytelling has been highlighted as an effective means to market an experience (C. Ryan \& Cave, 2005) and testimonials solicited from event participants can be used by event managers to tell the story of the event, and the well-being benefits provided by the event. Testimonials have been previously advocated to promote events and strengthen communities within and around events (e.g., Woosnam, Aleshinloye, Van Winkle, \& Qian, 2014), and testimonials reinforcing on behalf of, or in memory of, whom an individual is participating have been previously incorporated in event design (e.g., Relay for Life Candlelight Ceremony) and marketing communication (e.g., 2009 LIVESTRONG Challenge Overview Video). PERMA-based testimonials may be facilitated through new media technologies (e.g., photo and video sharing, or Twitter aggregating) to allow individuals to highlight moments related to different PERMA domains and can be featured at different stages of the event, as appropriate. Finally, the stories shared through testimonials, along with 
additional feedback regarding PERMA and wellbeing solicited through event evaluation, can be used to develop the social impact portfolio of an event.

\section{Public Health Implications}

The impact of the event experience on participant well-being and the positive benefits derived from activating the different domains of well-being can also be used as social impact evidence within applications for external funding and support. This type of social impact is significant as developed nations face an increasing health burden from major lifestyle-related diseases, including mental disorders (Egger \& Egger, 2012). In Australia, mental health was declared a National Health Priority area in 1996 because of its community impact; over $\$ 600$ million per year is spent on depression treatment costs and depression will be second only to heart disease as the leading medical cause of death and disability within 20 years (Department of Health and Ageing, 2013). Currently, up to 33\% of Australians reported experiencing depressive symptoms with $10 \%$ of these being in the severe range (Australian Psychological Society, 2012). Under these circumstances, developing new ways of integrating well-being into people's lives is increasingly important. Charity sport events such as the one described here may therefore play an important role in the so-called "lifestyle medicine," a new model of health care designed to manage lifestyle-related diseases and focus on changes in lifestyle patterns and behaviors to promote individual health and well-being (e.g., Egger \& Egger, 2012).

\section{Theoretical Advances and Future Directions}

This study represents an initial attempt at operationalizing PERMA in a nonclinical and group setting, and, as such, adds to our understanding of well-being as a multifaceted and dynamic process. Indeed, the presence of the five PERMA domains provides supporting evidence that wellbeing is a multidimensional construct (Diener, 2006). In addition, the results present evidence that PERMA well-being dimensions are present in this context, and therefore events may provide an additional mechanism to promote individuals' overall well-being (Diener et al., 1999). Nonetheless, the cooccurrence of PERMA dimensions evident in the overlapping themes demonstrates potential challenges with distinguishing these domains. Consequently, further examination to extend this exploratory work is necessary.

The emergence of nonsupporting themes suggests that further investigation of the PERMA domains in the charity sport event context. Although evidence of each domain was uncovered, nonsupporting themes such as lack of solidarity suggest that the event experience was not entirely positive for all participants. Having a less than positive experience at the event may temper the stimulation of PERMA domains. Sato, Jordan, and Funk (2014) have demonstrated that a positive event experience contributes to satisfaction with life domains (i.e., social life, personal achievement) and overall satisfaction with life, which align closely with the PERMA domains explored in the current study. Consequently, future research can attempt to delineate between the participant's subjective event experience and the activation and engagement of PERMA domains.

Based upon the findings of the current research, and the limitations noted earlier, a number of future research directions emerge, particularly with regard to the long-term and cumulative effects of the PERMA domains activated through these events, as well as comparisons across different types of events. Longitudinal data can be collected from event participants at different stages (pre, during, and postevent) to track changes in well-being and the domains of well-being. Data collected through focus groups with teams in their entirety, interviews with individual participants, and quantitative, survey-based data collection can be complemented by tools such as participant journaling or online blogs and discussion forums to provide greater insight into how well-being develops and changes throughout the event experience.

Furthermore, researchers can explore the cumulative effects of these factors. This exploration can evaluate how the activation of PERMA through similar events impacts additional aspects of participants' lives. The focus group participants indicated that the event experience, and the PERMA domains engaged through the experience, would prompt them to enter other events and attempt other challenges. Longitudinal data can be collected with event participants to track behavior and attitudes following the event, and the outcomes of event participation. 
Data can also be collected to compare well-being and PERMA outcomes across various contexts, within events, and between events. Data collected during these intervals can inform event managers regarding which aspects of well-being are activated and can be leveraged at different time periods among event participants. Other comparisons can include: the type of activity (e.g., walking, running, cycling), the participation context (e.g., individual vs. team participation; first-year versus multiyear participation), and geographical/cultural context (e.g., urban vs. rural; international vs. domestic). This comparison can draw attention to differences that may exist across charity sport events and their relationship with well-being.

An additional contextual comparison can be made through the examination of charity sport events with mass participation sport events not directly linked with a charity. A number of the quotes reflecting the different PERMA domains, specifically positive emotion, meaning, and accomplishment, were closely linked with the charities aligned with each event. A comparison with sport events that do not benefit a charity could evaluate whether the findings of the current research are unique to the charity sport event context. Similarly, a comparison between charity sport events, such as those examined within the current research, and charity events that do not involve sport (e.g., Movember, Shave-for-a-Cure) could be made to explore the relevance of sport on PERMA domains within the event context.

\section{Conclusion}

The current research represents initial exploration of PERMA within the charity sport event context. It is suggested that the social, physical activity, and charitable characteristics of charity sport events are particularly suited to the operationalization of PERMA in a nonclinical, group-based setting. The findings provided strong support for four of the five PERMA domains (i.e., positive emotion, relationships, accomplishment, and meaning) within charity sport events, and some support for engagement. Although charity sport events may foster well-being outcomes through PERMA, the results raise a number of questions concerning the cumulative and longitudinal effects of these outcomes. Further research might investigate whether the presence of several
PERMA domains leads to longer lasting well-being outcomes, higher levels of well-being, or simply an increased probability of achieving a sense of wellbeing. Finally, the results have important implications for the social impact of such events, and their role in broader public health policies.

\section{Appendix: Focus Group Interview Guide}

1. Considering the training required, the fundraising required, and the charity connected to this event, describe what-if anything-you have learned from preparing for the event?

a. Did the event allow you to explore parts of yourself/your identity that you don't get to express in everyday life?

b. Can you describe how the experience has influenced your relationships with your team? Other participants? Family and friends?

c. Did you find yourself working together with other participants? If so, how?

2. What was the most enduring positive emotion that you experienced during the event? After the event? Can you recall any less positive emotions?

3. <NOTE: IF NECCESARY> Did you ever find yourself lost in a moment during the event experience? Could you provide an example of when and how this occurred?

4. Were there any highlights of "sharing a moment" with other team members or friends and family?

5. Thinking about the training, the other participants, and the cause, what does this event mean to you personally?

6. Please elaborate on what you felt as you crossed the finish line at the completion of the event?

a. Can you describe your biggest sense of achievement?

\section{References}

Australian Psychological Society. (2012). Stress and wellbeing in Australia in 2012: A state of the nation survey. Retrieved on April 18, 2016, from https://www.psychol ogy.org.au/Assets/Files/Stress\%20and\%20wellbeing\%20 in\%20Australia\%202012\%20Report_FINAL-web.pdf

Baumeister, R. (1992). Meanings in life. Hillsdale, NJ: Erlbaum.

Biddle, S., Boutcher, S. H., \& Fox, K. R. (2000). Physical activity and psychological well-being. New York: Routledge. 
Brajša-Žganec, A., Merkaš, M., \& Šverko, I. (2011). Quality of life and leisure activities: How do leisure activities contribute to subjective well-being? Social Indicators Research, 102(1), 81-91.

Cheong, M., \& Lee, V. (2010). Twittering for Earth: A study on the impact of microblogging activism on Earth Hour 2009 in Australia. Lecture Notes in Computer Science, 5991, 114-123.

Coghlan, A., \& Filo, K. (2013). Using the constant comparison method and qualitative data to understand participants' experiences at the nexus of tourism, sport and charity events. Tourism Management, 35, 122-131.

Corbin, J., \& Strauss, A. (Eds.). (2008). Basics of qualitative research: Techniques and procedures for developing grounded theory. Thousand Oaks, CA: Sage.

Csikszentmihalyi, M. (1996). Finding flow: The psychology of engagement with everyday life. New York: Basic Books.

Deci, E. L., \& Ryan, R. M. (2000). The "what" and "why” of goal pursuits: Human needs and the self-determination of behavior. Psychological Inquiry, 11, 227-268.

Department of Health and Ageing. (2013). Beyond blue: The national depression initiative. Retrieved on April 18, 2016, from https://www.chf.org.au/pdfs/hvo/hvo-2009-5 -beyondblue-national-depression-initiative.pdf

Diener, E. (2000). Subjective well-being: The science of happiness and a proposal for a national index. American Psychologist, 55(1), 34-43.

Diener, E. (2006). Guidelines for national indicators of subjective well-being and ill-being. Applied Research in Quality of Life, 10, 1-7.

Diener, E., \& Seligman, M. E. P. (2002). Very happy people. Psychological Science, 13, 81-84.

Diener, E., Suh, E., Lucas, R. E., \& Smith, H. L. (1999). Subjective well-being: Three decades of progress. Psychological Bulletin, 125(2), 276-302.

Duvall, J. (2011). Enhancing the benefits of outdoor walking with cognitive engagement strategies. Journal of Environmental Psychology, 31, 27-35.

Egger, G., \& Egger, S. (2012). Lifestyle medicine: The Australian experience. American Journal of Lifestyle Medicine, 6(1), 26-30.

Edwards, P., \& Tsouros, A. D. (2008). A healthy city is an active city: A physical activity planning guide. Copenhagen, Denmark: World Health Organization.

Elo, S., \& Kyngas, H. (2008). The qualitative content analysis process. Journal of Advanced Nursing, 62(1), 107-115.

Filep, S. (2014). Moving beyond subjective well-being: A tourism critique. Journal of Hospitality \& Tourism Research, 38, 266-274.

Filo, K., Funk, D. C., \& O’Brien, D. (2008). It's really not about the bike: Exploring attraction and attachment to the events of the Lance Armstrong Foundation. Journal of Sport Management, 22, 501-525.

Filo, K., Funk, D. C., \& O’Brien, D. (2009). The meaning behind attachment: Exploring camaraderie, cause, and competency at a charity sport event. Journal of Sport Management, 23, 361-387.
Filo, K., Funk, D. C., \& O’Brien, D. (2011). Examining motivation for charity sport event participation: A comparison of recreation-based and charity-based motives. Journal of Leisure Research, 43, 491-518.

Fontana, A., \& Frey, J. (1994). Interviewing: The art of science. In N. Denzin \& Y. Lincoln (Eds.), Handbook of qualitative research (pp. 361-376). Thousand Oaks, CA: Sage.

Forgeard, M. J. C., Jayawickreme, E., Kern, M., \& Seligman, M. E. P. (2011). Do the right thing: Measuring wellbeing for public policy. International Journal of WellBeing, 1(1), 70-106.

Fox, K. R. (1999). The influence of physical activity on mental well-being. Public Health Nutrition, 2(3), 411-418.

Frankl, V. E. (1966). Self-transcendence as a human phenomenon. Journal of Humanistic Psychology, 6, 97-106.

Fredrickson, B. L. (1998). What good are positive emotions? Review of General Psychology, 2, 300-319.

Fredrickson, B. L. (2001). The role of positive emotions in positive psychology: The broaden and build theory of positive emotions. American Psychologist, 56, 218-226.

Fredrickson, B. L., \& Cohn, M. (2008). Positive emotions. In M. Lewis, J. Haviland-Jones, \& L. Barrett (Eds.), Handbook of emotions (pp. 777-798). New York: Guildford Press.

Funk, D., Jordan, J., Ridinger, L., \& Kaplanidou, K. (2011). Capacity of mass participation sport events for the development of activity commitment and future exercise intention. Leisure Sciences, 33, 250-268.

Gallagher, M., Lopez, S., \& Preacher, K. (2009). The hierarchical structure of well-being. Journal of Personality, 77(4), 1026-1049.

Higgins, J., \& Lauzon, L. (2003). Finding the funds in fun runs. International Journal of Nonprofit and Voluntary Sector Marketing, 8(4), 363-377.

Hills, P., \& Argyle, M. (2001). Happiness, introversionextraversion and happy introverts. Personality and Individual Differences, 30, 595-608.

Hsieh, H., \& Shannon, S. (2005). Three approaches to qualitative content analysis. Qualitative Health Research, 15, 1277-1288.

Huppert, F., \& So, T. (2013). Flourishing across Europe: Application of a new conceptual framework for defining well-being. Social Indicators Research, 110(3), 837-861.

Jackson, S. A., \& Csikszentmihalyi, M. (1999). Flow in sports. Champaign, IL: Human Kinetics.

Kahneman, D., \& Krueger, A. B. (2006). Developments in the measurements of subjective well-being. The Journal of Economic Perspectives, 20, 3-24.

Kanste, O. (2011). Work engagement, work commitment and their association with well-being in health care. Scandinavian Journal of Caring Sciences, 25, 754-761.

Keyes, C. L. M. (1998). Social well-being. Social Psychology Quarterly, 61, 121-140.

Keyes, C. L. M. (2002). The mental health continuum: From languishing to flourishing in life. Journal of Health and Social Behavior, 43(2), 207-222.

Keyes, C. L. M. (2007). Promoting and protecting mental health as flourishing: A complementary strategy for 
improving national mental health. American Psychologist, 62(2), 95-108.

Kler, B. K., \& Tribe, J. (2012). Flourishing through SCUBA: Understanding the pursuit of dive experiences. Tourism in Marine Environments, 8(1-2), 1-2.

Krueger, R. A., \& Casey, M. A. (2002). Designing and conducting focus group interviews. In R. Krueger, M. Casey, J. Donner, S. Kirsch, \& J. Maack (Eds.), Social analysis, selected tools and techniques (pp. 4-23). Washington, DC: World Bank.

Lee, R. M., \& Robbins, S. B. (1998). The relationship between social connectedness and anxiety, self-esteem, and social identity. Journal of Counseling Psychology, 45, 338-345.

Maddock, J. (2006). Evaluation of community-based physical activity programs. Evaluation and Program Planning, 29, 240-241.

Marsh, H. W., \& Jackson, S. A. (1999). Flow experience in sport: Construct validation of multidimensional, hierarchical state and trait responses. Structural Equation Modeling: A Multidisciplinary Journal, 6(4), 343-371.

Maslow, A. H. (1968). Toward a psychology of being (Vol. 5). New York: Thomas Nelson Australia.

Mayring, P. (2000). Qualitative content analysis. Forum: Qualitative Social Research, 1(2). Retrieved November 7, 2014, from http://www.qualitative-research.net/index. php/fqs/article/viewArticle/1089/2385\#g4

Murphy, N. M., \& Bauman, A. (2007). Mass sporting and physical activity events-are they "bread and circuses" or public health interventions to increase population levels of physical activity? Journal of Physical Activity \& Health, 4, 193-202.

Mutrie, N., \& Faulkner, G. E. J. (2004). Physical activity: Positive psychology in motion. In P. A. Linley \& S. Joseph (Eds.), Positive psychology in practice (pp. 146164). Hoboken, NJ: John Wiley \& Sons, Inc.

Nordvall, A., Pettersson, R., Svensson, B., \& Brown, S. (2014). Designing events for social interaction. Event Management, 18(2), 127-140.

Peloza, J., \& Hassay, D. (2007). A typology of charity sport behaviours: Toward a holistic view of helping. Journal of Nonprofit and Public Sector Marketing, 17(1/2), 135-151.

Peterson, C. (2006). A primer in positive psychology. New York: Oxford University Press.

Peterson, C., Park, N., \& Sweeney, P. J. (2008). Group wellbeing: Morale from a positive psychology perspective. Applied Psychology, 57, 19-36.

Rasciute, S., \& Downward, P. (2010). Health or happiness? What is the impact of physical activity on the individual? KYKLOS, 63(2), 256-270.

Reis, H. T., Sheldon, K. M., Gable, S. L., Roscoe, J., \& Ryan, R. M. (2000). Daily well-being: The role of autonomy, competence, and relatedness. Personality and Social Psychology Bulletin, 26, 419-435.

Robertson, I. T., \& Cooper, C. L. (2010). Full engagement: The integration of employee engagement and psychological well-being. Leadership and Organization Development Journal, 31(4), 324-336.

Ryan, C. (1995). Researching tourist satisfaction: Issues, concepts, problems. New York: Routledge.

Ryan, C., \& Cave, J. (2005) Structuring destination image: A qualitative approach. Journal of Travel Research, 44, 143-150.

Ryan, R. M., \& Deci, E. L. (2000). Self-determination theory and the facilitation of intrinsic motivation, social development, and well-being. American Psychologist, 55(1), 68-78.

Sato, M., Jordan, J. S., \& Funk, D. C. (2014). The role of physically active leisure for enhancing quality of life. Leisure Sciences, 36(3), 293-313.

Scannell, E. D., Allen, F. C. L., \& Burton, J. (2002). Meaning in life and positive and negative well-being. North American Journal of Psychology, 4(1), 93-112.

Schulenkorf, N., Thomson, A., \& Schlenker, K. (2011). Intercommunity sport events: Vehicles and catalysts for social capital in divided societies. Event management, 15(2), 105-119.

Seidman, I. (1998). Interviewing as qualitative research. New York: Teachers College Press.

Seligman, M. E. P. (2004). Can happiness be taught? Deedalus, 133(2), 80-87.

Seligman, M. E. P. (2011). Flourish: A new understanding of happiness, well-being-and how to achieve them. London: Nicholas Brealey Publishing.

Seligman, M. E. P., \& Csikszentmihalyi, M. (2000). Positive psychology: An introduction. American Psychologist, 55(1), 5-14.

Seligman, M. E. P., Parks, A. C., \& Steen, T. (2004). A balanced psychology and a full life. Philosophical Transactions of the Royal Society, 359, 1379-1381.

Sherry, E. (2010). (Re) engaging marginalized groups through sport: The Homeless World Cup. International Review for the Sociology of Sport, 45(1), 59-71.

Slade, M. (2010). Mental illness and well-being: The central importance of positive psychology and recovery approaches. BMC Health Services Research, 10, 26-40.

Stevinson, C., \& Hickson, M. (2013). Exploring the public health potential of a mass community participation event. Journal of Public Health, 82, 1-7.

Theodorakis, N. D., Kaplanidou, K., \& Karabaxoglou, I. (2015). Effect of event service quality and satisfaction on happiness among runners of a recurring sport event. Leisure Sciences, 37(1), 87-107.

Tugade, M. M., \& Fredrickson, B. L. (2004). Resilient individuals use positive emotions to bounce back from negative emotional experiences. Journal of Personality and Social Psychology, 86, 320-333.

World Health Organization. (2013). Mental health: A state of well-being. Retrieved March 14, 2014, from http:// www.who.int/features/factfiles/mental_health/en/

Woosnam, K. M., Aleshinloye, K. D., Van Winkle, C. M., \& Qian, W. (2014). Applying and expanding the theoretical framework of emotional solidarity in a festival context. Event Management, 18(2), 141-151. 